\title{
Aerobic Training Models: Circuit and Body Language Towards Reduction of Fat Body Viewed from Mother Body Weight
}

\author{
Karlina Dwijayanti ${ }^{1}$, Arif Rohman Hakim ${ }^{1 *}$
}

\author{
${ }^{1}$ Universitas Tunas Pembangunan, Surakarta 57139, Indonesia \\ *Corresponding author. Email: arifrohman.hakim8686@gmail.com
}

\begin{abstract}
Obesity is one of the risks of various diseases and can reduce the beauty of the body, especially mothers. From the survey data conducted by many mothers always complained by the name of gaining weight because they did not exercise while the food patterns were also not regulated, they tend to prefer fast food. Therefore, one type of exercise used to reduce body fat is to do aerobic exercise. The success of decreasing body fat can be seen with aerobic exercise training models through the Circuit training model and body language training. In addition, it can also be seen from the consistency of exercise, adequate diet and rest, so that instructors need innovation or variation by applying appropriate training models. The research method used in this study is the experimental method. This research was divided into two treatment groups namely the experimental group and the control group. The two groups were tested for their initial conditions, before being given different treatments. In the experimental group the implementation uses the circuit training model, while the control group uses the body language training model in the implementation. At the end of the treatment the two groups were measured using tests and measurements using a skinfold calliper. The data analysis technique in this study used a $2 \times 3$ factorial design variance analysis (ANAVA) technique at $\alpha=0.05$. With the normality test (Lilliefors test) and the Homogeneity Variance test (with Bartlet test). The results of this study indicate that: 1 . There are differences in the effect of the application of the circuit training model and the body language training model on decreasing body fat. 2 . There is a difference in the effect of gymnastics mothers who have underweight, normal weight, and overweight weight on the reduction in body fat. 3 . There is no interaction of influence between exercise model and body weight on body fat reduction.
\end{abstract}

Keywords: obesity, aerobic, mother

\section{INTRODUCTION}

Lifestyle of some people who lead to modern life patterns. Making a poor diet because it prefers fast food, high in calories and contains a lot of fat while the activity to move alone is very less. The entry of excessive calories and the use of very few calories will result in obesity. Besides making self-confidence due to being overweight or obese can also be a source of risk for various metabolic diseases such as diabetes mellitus, hypertension, coronary heart disease, stroke and dyslipidaemia, etc. But an active lifestyle can be created by starting to do physical activities such as gymnastics because gymnastics is one of the good activities for the development of courage, confidence in yourself and belief. According to [1] Gymnastics is a form of body movements that are planned and arranged regularly with the aim of improving posture and body shape, fostering and developing harmonious skills and personalities.

Aerobic exercise is a sport that is in great demand because it makes the body healthy and fit, it can be done anywhere with music that always makes you eager to move and does not need to pay quite expensive. Everyone can do aerobic exercise together. Considering the importance of aerobic exercise for health and decreasing body fat, various aerobic exercise training models should be developed so that the movements displayed can be structured and wellcoordinated. Based on observations there are three problems regarding the difficulty of decreasing body fat in the following gymnastic mothers. First, the lack of intensity of exercise for women doing aerobics because of constrained daily routine makes it inconsistent to do the exercise program. Secondly, there is no suitable aerobics exercise model book and can be used as instructor guidelines for body fat reduction so that the weight of the members can be ideal. Third, the lack of variations in the instructor's movements so that they look monotonous and make the members bored.

One form of aerobic exercise model is the circuit training model. According to [2] circuit training is an effective and structured form of physical fitness training, aimed at developing and improving physical fitness related to strength, speed and power hold on. Aerobic gymnastic circuit training model is an aerobic gymnastics variation which is done by combining aerobic exercise and fitness movements accompanied by music and performed by several stations (post) and at each station aerobic exercise performers have determined the type of movement. Perpetrators in each station consists of 6-8 people. The following is the movement of each station: 1 . Move along with the instructor (2 minutes). 2.Weighted punches (2 
minutes). 3.Quick suicide sprints (2 minutes). 4. Jack (2 minutes). 5.4x4-4-point hops / Power jumps (2 minutes). 6. Step up lunges (2 minutes). 7. V-step (2 minutes). 8. Knee Up ( 2 minutes). In addition to the Circuit Training Model there is also a body language gymnastic model applied. Body language gymnastics is gymnastics that prioritizes movements for flexibility and the formation of body muscles, especially reproductive organs [3]. Body language gymnastics is gymnastics whose movements are performed by holding back muscle contractions [4]. Can increase pelvic and abdominal muscle strength done at least $3 \mathrm{x}$ a week with variations in the movements of the instructor. From the problems above, to get the ideal body of the Surakarta gymnastics mothers, the aerobic exercise model of circuit training and body language training is needed so that the reduction in body fat can be achieved. This study aims to determine the difference in the effect of the application of the circuit training model and the body language training model on decreasing body fat; the difference in the influence of mothers' gymnastics who have underweight, normal weight, and overweight weight on the reduction in body fat; and is there an interaction of influence between the exercise model and body weight on the reduction in body fat.

\section{METHOD}

The research method used in this study is the experimental method. $2 \times 3$ factorial design, with a view to knowing the effect of two independent variables on the dependent variable.

Table 1 Research design

\begin{tabular}{|lccc|}
\hline \multirow{2}{*}{ Aerobic Exercise Training Model } & \multicolumn{3}{c|}{ Decreased Body Fat } \\
\cline { 2 - 4 } & underweight $\left(\boldsymbol{b}_{\mathbf{1}}\right)$ & normal weight $\left(\boldsymbol{b}_{\mathbf{2}}\right)$ & Overweight $\left(\boldsymbol{b}_{\mathbf{3}}\right)$ \\
\hline circuit training $\left(a_{1}\right)$ & $a_{1} b_{1}$ & $a_{1} b_{2}$ & $a_{1} b_{3}$ \\
Body language training $\left(a_{2}\right)$ & $a_{2} b_{1}$ & $a_{2} b_{2}$ & $a_{2} b_{3}$ \\
\hline
\end{tabular}

This research was carried out from April-May 2019 in Surakarta City Gymnastics Centers for one and a half months (six weeks) with three exercises in one week. The subjects of this study were 76 mothers of gymnastics studio in Surakarta. Sampling is done by purposive random sampling by looking at the population as groups. This research was divided into two treatment groups namely the experimental group and the control group. The two groups were tested for their initial conditions, before being given different treatments. In the experimental group the implementation uses the circuit training model, while the control group uses the body language training model in the implementation. At the end of the treatment the two groups were measured using tests and measurements using a skinfold calliper from [5].The data analysis technique in this study used a $2 \times 3$ factorial design variance analysis (ANOVA) technique at $\alpha=0.05$. With the normality test (Lilliefors test) and the Homogeneity Variance test (with Bartlet test). The purpose of data analysis is to solve research problems, show the relationship between phenomena contained in research, provide answers to hypotheses raised in research and materials to make conclusions [6].

\section{RESULTS AND DISCUSSION}

Before a different treatment is carried out, a balance test is carried out between the control group and the experimental group by assessing the initial values (pre-test) of the two groups. The test uses a t test with criteria based on alpha value $(\alpha=0.05)$ if the probability value $>0.05$ then it is concluded that both groups have the same initial value, conversely if the probability value $<0.05$ then it is concluded that the two groups have different initial values. The calculation results are summarized in the table 2 .

Table 2 Summary of the initial similarity tests

\begin{tabular}{|lccccc|}
\hline \multicolumn{1}{|c}{ Treatment } & Mean & Std. Deviation & t count & p & Conclusion \\
\hline circuit training & 25.6906 & 7.92005 & 0.159 & 0.874 & Similar \\
body language training & 25.4006 & 7.50272 & & & \\
\hline
\end{tabular}

From the table above, it can be seen that the value of $p=$ $0.878>\alpha=0.05$ means that there is no average difference between the groups of aerobic gymnastics training circuit models and aerobic gymnastics body language training models. This means that the assumption of equality of initial values is met.

The results of normality test data in this study use the Shapiro-Wilk method because of the large number of samples $\leq 50$. The normality test criteria are if the probability value (sig.) $>0.05$ then it is declared to have normal distribution whereas if the probability value $<0.05$ then it is declared not normally distributed. The results of the normality test data carried out in each group are as follows at Table 3: 
Table 3 Normality Test Results

\begin{tabular}{|llcccc|}
\hline & & \multicolumn{3}{c}{ Shapiro-Wilk } & \\
\hline difference & Statistic & df & Sig. & Conclusion \\
& circuit training underweights & 0.973 & 12 & 0.941 & Normal \\
& circuit training normal weight & 0.868 & 12 & 0.062 & Normal \\
& circuit training overweight & 0.942 & 12 & 0.525 & Normal \\
& body language underweight & 0.935 & 12 & 0.431 & Normal \\
& body language normal weight & 0.920 & 12 & 0.282 & Normal \\
& body language overweight & 0.931 & 12 & 0.395 & Normal \\
\hline
\end{tabular}

The results of the test using the circuit training model and the body language model of Shapiro Wilk method in observing the reduction in fat of gymnastic mothers with skinfold calliper known respectively for the underweight training circuit model, the normal weight training circuit model, the overweight training circuit model, the body language underweight training model, normal weight body language models, and overweight body language models have probability values of $0.941,0.062,0.525,0.431,0.282$ and 0.395 . The six groups have probability values $>0.05$ so that they are declared to have normal distribution. Based on these statements, it is assumed that normality is fulfilled. Homogeneity test aims to determine the similarity of variance of the six groups, namely a combination of treatment groups and weight criteria. Homogeneity testing uses Levenne's test. The criteria used is. If probability $\geq$ 0.05 then Ho is received (all four homogeneous groups) otherwise If sig. $<0.05$ then Ho is rejected (all four heterogeneous groups). Homogeneity test results of data between the six groups are as follows:

Table 4 Homogeneity Test Results

\begin{tabular}{|lllll|}
\hline F & df1 & df2 & Sig. & conclusion \\
\hline 1.616 & 5 & 66 & 0.168 & homogeny \\
\hline
\end{tabular}

The calculation results obtained calculated $\mathrm{F}$ value of 1.616 and a probability of 0.168 whose value $>0.05$. it means that the group's kenam on observation is homogeneous. Based on this statement, the homogeneity assumption is fulfilled. In the test factors the test equipment used is 2 way ANOVA. While the inter-group test uses post hoc Tukey. In statistical testing the test criteria are if the probability value $<0.05$ then it is concluded there are differences between groups with other groups. Conversely, if the probability value $>0.05$, it is concluded that there is no difference between group 1 and other groups. The test results are attached as Table 5:

Table 5 ANOVA test and comparison between groups on treatment factors.

\begin{tabular}{|llll|}
\hline Group & mean & F count & $p$ \\
\hline circuit training & 4.246 & 6.568 & 0.013 \\
body language training & 3.383 & & \\
\hline
\end{tabular}

In the treatment factor on Table 5, the calculated $\mathrm{F}$ value is 6.568 and the probability value is 0.013 . probability value $<0.05$ which means there is an influence of treatment factors on decreasing body fat. The average reduction in body fat in the training circuit model was 4.246 while in the body language training model the decrease was 3.383 . when compared to the two, it is found that there is more reduction in the circuit training model than in the body language training model. This means that the decrease in body fat in the treatment circuit training model is better than the body language training model.

Table 6 ANOVA test and comparison between groups on weight factors

\begin{tabular}{|lll|}
\hline Factor & F count & P \\
\hline Weight & 22.497 & 0.000 \\
\hline Group & grup1 & grup2 \\
\hline Normal weight & 2.970 & \\
Underweight & 3.062 & \\
Overweight & & 5.412 \\
\hline
\end{tabular}

One the weight factor on Table 6 , the calculated $\mathrm{F}$ value is 22,497 and the probability value is 0,000 . $p$ value $<0.05$ which means that there is an influence of weight factors on decreasing body fat. The results of further tests on the weight factor obtained that the normal weight and underweight groups i.e. the average decrease in body fat is almost the same, namely at normal weight of 2,970 and underweight of 3,062. Whereas in overweight the decline was 5,412 , the biggest decrease compared to both. 
Table 7 Interaction Test

\begin{tabular}{|lll|}
\hline Factor & F & Sig. \\
\hline Treatment weight & 0.042 & 0.959 \\
\hline
\end{tabular}

The results of testing with 2-way ANOVA statistics on Table 7 on the interaction factor obtained the calculated $\mathrm{F}$ value of 0.042 and the probability of 0.959 . Probability value $>0.05$ means that there is no interaction effect on decreasing body fat. To find out whether there is interaction can be seen from the means plot interaction graph.

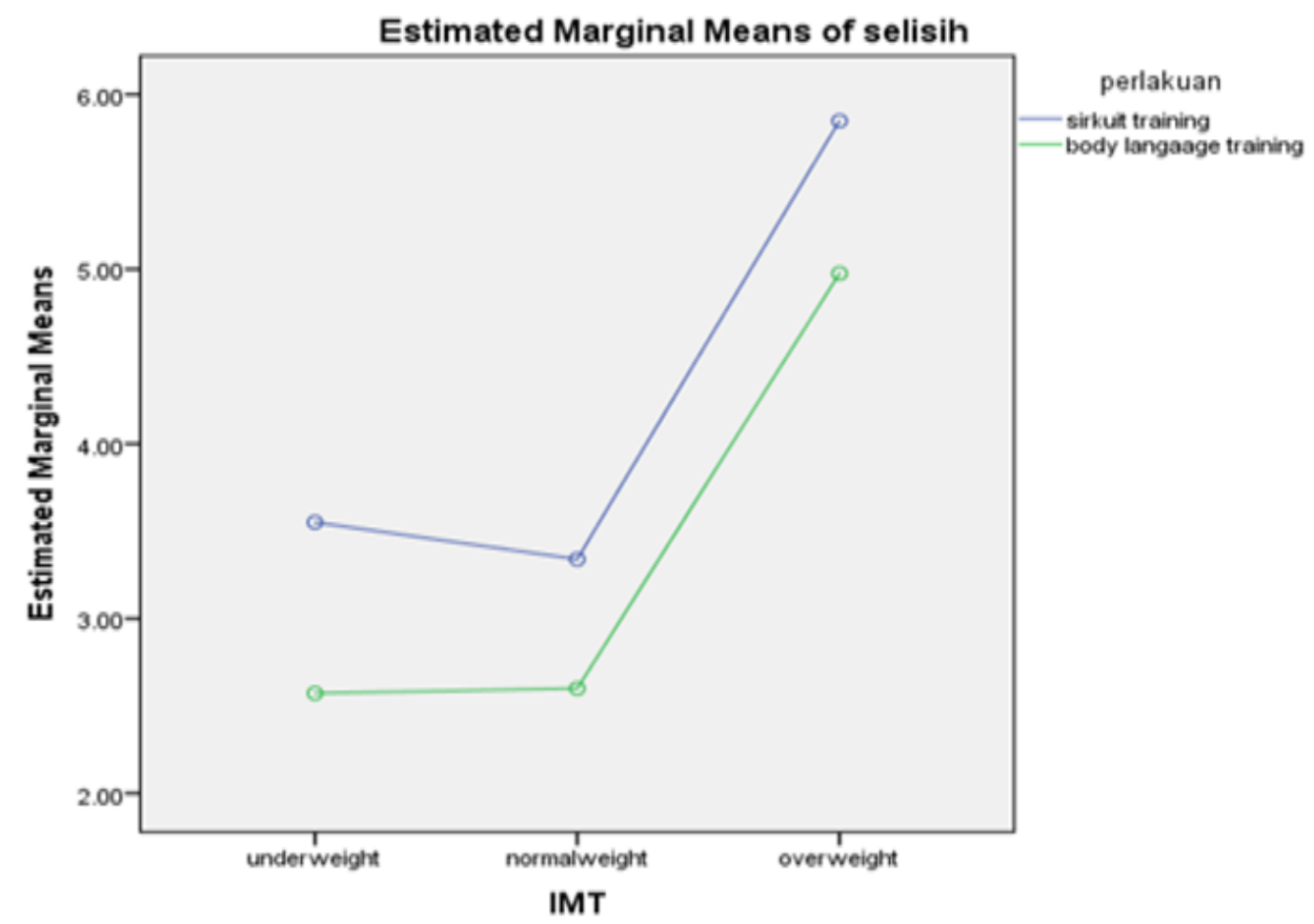

Figure 1 Means plots the interaction of body weight and the treatment model of the exercise

In Fig. 1. can be seen that between the blue line (circuit training model) and the green line (body language training model) tend to be parallel. The treatment circuit training model is always higher than the body language training model. so, there is no interaction of aerobic exercise models with a decrease in body fat.

\section{CONCLUSION}

There is an effect of the treatment on decreasing body fat i.e. the training circuit treatment group is better than the body language. The average reduction in body fat in the training circuit model was 4,246 while in the body language training model the decrease was 3,383. when compared to the two, it is found that there is more reduction in the circuit training model than in the body language training model. This means that the decrease in body fat in the treatment circuit training model is better than the body language training model.

There is an influence of underweight, normal weight and overweight on the decrease in body fat. i.e. the normal weight and underweight groups obtained decreased body fat tends to be the same. Whereas in the overweight group the decrease was significantly higher than in the normal weight and underweight groups. On the IMT factor, the calculated $\mathrm{F}$ value is 22.497 and the probability value is 0.000 . $\mathrm{p}$ value $<0.05$ which means that there is an effect of BMI factor on decreasing body fat. The results of further tests on the BMI factor found that the normal weight and underweight groups i.e. the average decrease in body fat was almost the same, namely the normal weight of 2,970 and underweight of 3,062 . Whereas in overweight the decline was 5,412 , the biggest decrease compared to both

There is no interaction between aerobic exercise models and body weight to decrease body fat. The results of testing with 2-way ANOVA statistics on the interaction factor obtained the calculated $F$ value of 0.042 and the probability of 0.959 . Probability value $>0.05$ means that there is no interaction effect on decreasing body fat.

\section{REFERENCES}

[1] Karlina Dwijayanti, "Perbedaan Pengaruh Latihan Senam Cerdas Bugar Indonesia (SBCI) 2013 dan Senam Aerobic Terhadap Peningkatan Kesegaran 
[4] M. Dinata, Senam Aerobik dan Peningkatan Kesegaran Jasmani : Lampung: Cerdas Jaya, 2002.

[5] Ismaryati, Tes Dan Pengukuran Olahraga. Surakarta: Sebelas Maret University Press, 2006.

[6] P. D. Sugiyono, metode penelitian kuantitatif, kualitatif, dan R\&D. 2016.

[3] M. Dinata, Rahasia Latihan Sang Juara Menuju

Prestasi Dunia. Jakarta: Cerdas Jaya, 2005. 